\title{
SANS investigation of precipitate microstructure in nickel-base superalloys Waspaloy and DT750
}

\section{P. Strunz ${ }^{1,2, *}$ J. Zrník ${ }^{3}$, T. Seliga ${ }^{4}$ H. J. Penkalla ${ }^{4}$}

\author{
${ }^{1}$ Nuclear Physics Institute, 25068 Řež near Prague, Czech Republic \\ ${ }^{2}$ Laboratory for Neutron Scattering, ETHZ \& PSI, CH-5232 Villigen PSI, Switzerland \\ ${ }^{3}$ Technical University of Košice, Dept. of Materials Science, Park Komenského 11, 04001 \\ Košice, Slovakia \\ ${ }^{4}$ Research Center Jülich, Institute for Materials and Processes in Energy Systems, D-52425 \\ Jülich, Germany \\ *Contact author; e-mail: strunz@ujf.cas.cz
}

Keywords: superalloys, precipitation, small-angle neutron scattering

\begin{abstract}
Microstructure of Waspaloy and DT750 Ni-base superalloys was investigated after the heat treatment as well as after long thermal exposure by Small-Angle Neutron Scattering (SANS). The SANS results clearly showed that there are large differences even between samples of the DT750 superalloy produced using different facilities. The modified heat treatment used for DT750 suppressed the formation of secondary precipitates. A strong influence of the thermal exposure on the superalloy microstructure was observed which can have an impact on the mechanical properties.
\end{abstract}

\section{Introduction}

The nickel-base superalloys are multicomponent alloy systems which are used at severe working conditions (rotors, discs or blades in turbines). The structure stability and creep resistance of superalloys is dependent on morphology and volume fraction of precipitates, predominantly $\gamma^{\prime}$, which strengthen the $\gamma$-phase matrix [1]. Various techniques (TEM, SEM, $\mathrm{X}$-ray, neutron diffraction) are necessary in order to characterize the superalloy microstructure, especially its $\gamma^{\prime}$-precipitate morphology.

Waspaloy (WASPALOY is a trademark of the United Technology Corporation) is a nickelbase polycrystalline superalloy [2], strengthened by $\gamma^{\prime}$ precipitates with bimodal size distribution, having excellent high-temperature strength and good resistance to corrosion, notably to oxidation. It is used for aerospace and gas turbine engine components at service temperatures up to $700^{\circ} \mathrm{C}$ for critical rotating applications (compressor and rotor discs, shafts, rings). Although this and similar superalloys were extensively studied by various macroscopic and microscopic techniques (see e.g. [3] and references therein), still deeper understanding of the processes taking place at the precipitate level during long-term thermal exposure is necessary 
in order to optimize the microstructure and thus to improve the high temperature microstructural stability. Moreover, the need to develop new superalloys enabling still higher operational temperatures accelerates the necessity of microstructural investigations, also by nontraditional techniques. The SANS method [4] can contribute substantially to the morphology investigation of $\gamma^{\prime}$ precipitates in nickel base superalloys [5], frequently even in-situ [6-8]. The present SANS experiment was aimed to provide bulk information on the $\gamma$ '-precipitate morphology in long-term thermally exposed Waspaloy and in the superalloy denoted DT750, which is derived from Waspaloy by the modification of the composition and heat treatment.

\section{Experimental}

Waspaloy (composition in wt\%: Fe 0.57, Cr 19.22, Nb 0.01, Ti 3.13, Al 1.22, C 0.033, Co 19.35 , Mo 4.52 , Ni balance) was solution annealed at $1080{ }^{\circ} \mathrm{C}$ for $4 \mathrm{~h}$ with subsequent cooling to $850{ }^{\circ} \mathrm{C}$ with a rate of $4 \mathrm{~K} / \mathrm{min}$, then air cooled (AC) to room temperature (RT), followed by two-step precipitation heat treatment at $850{ }^{\circ} \mathrm{C}$ for $4 \mathrm{~h}$ and at $760^{\circ} \mathrm{C}$ for $16 \mathrm{~h}$ (steps separated by $\mathrm{AC}$ to $\mathrm{RT}$ ). The microstructure of Waspaloy after heat treatment is shown in figure 1.

In order to avoid freckle formation, the composition of Waspaloy was modified (in wt\%: Fe 0.61 , Cr 19.3, Nb 1.46, Ti 1.61, Al 1.45, C 0.027, Co 19.3, Mo 4.45, Ni bal.) and the experimental alloy was denoted DT750. The heat treatment of this alloy was simplified: DT750 has been solution treated at $1080{ }^{\circ} \mathrm{C}$ for $4 \mathrm{~h}$, cooled with cooling rate of $4 \mathrm{~K} / \mathrm{min}$ directly (i.e. without cooling to RT) to the precipitation temperature of $800^{\circ} \mathrm{C}$ and aged for $16 \mathrm{~h}$.

The microstructure of these two superalloys obtained using the above described treatments was investigated by SANS. At the same time, the morphological changes (precipitate size and their volume fraction) resulting from the long thermal exposure of the alloys were examined in dependence on the temperature and time of exposure (see table 1 for the overview).

The presented SANS measurement was carried out at SANS-II facility of SINQ user lab at Paul-Scherrer Institut Villigen, Switzerland [9]. Platelet samples of about $2 \mathrm{~mm}$ thickness and $14 \mathrm{~mm}$ diameter were measured at room temperature. The scattering data were collected at several experimental geometries (the sample-to-detector distance varied from $1 \mathrm{~m}$ to $6 \mathrm{~m}$, and the neutron wavelength $\lambda$ from $4.55 \AA$ to $19.6 \AA$ ). The covered scattering vector $\boldsymbol{Q}$ range was $1 \times 10^{-3} \AA^{-1}-0.35 \AA^{-1}$ (i.e. $1 \times 10^{-2} \mathrm{~nm}^{-1}<Q<3.5 \mathrm{~nm}^{-1}$ ), where the magnitude $Q=|Q|=$ $\left|\mathbf{k}-\mathbf{k}_{0}\right|, \mathbf{k}_{0}$ and $\mathbf{k}$ being the wavevectors of incident and scattered neutron, respectively, and $|\mathbf{k}|$ $=\left|\mathbf{k}_{0}\right|=2 \pi / \lambda$. The measured raw data were corrected for background scattering and calibrated

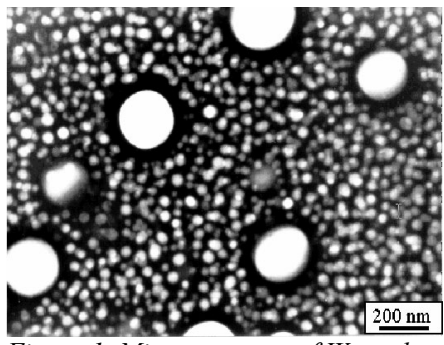

Figure 1. Microstructure of Waspaloy after the standard heat treatment. to the absolute scale. The magnitude of the resulting differential macroscopic cross section is proportional to the square scattering contrast of the $\gamma^{\prime}$ precipitates and their volume fraction. However, the exact determination of scattering contrast is practically not possible (because of the chemical-composition uncertainty of $\gamma$ and $\gamma$ ' phases), hindering thus a direct determination of the volume fraction. Therefore, this quantity has to be derived indirectly from the modelling of the microstructure and scattering curves. 


\section{Evaluation and results}

The full measured scattering profiles collected at RT for the different thermally exposed samples are presented in figures 2 and 3 for the standard Waspaloy and DT750, respectively. The diagrams show the scattering cross section $d \Sigma / d \Omega$ vs. scattering vector magnitude $Q$.

SANS data were processed using the NOC program [7]. The procedure is based on the numerical simulation of a scattering profile using a three-dimensional (3D) microstructural model of a particle system. The modelled scattering curve thus also contains the interparticle-interference effect. The calculated profile is then fitted to the experimental curve in order to find the optimum microstructural parameters (i.e. $\gamma^{\prime}$-precipitate size, their volume fraction, eventually center-to-center distance) which fit best the experimental data. In the used model, the form of $\gamma^{\prime}$ precipitate was approximated - in agreement with the indication obtained by electron microscopy (see figure 1) - by the spherical shape. Size distribution was simulated by a log-normal curve. Selected fitted curves are displayed in figures 2 and 3 as well by lines

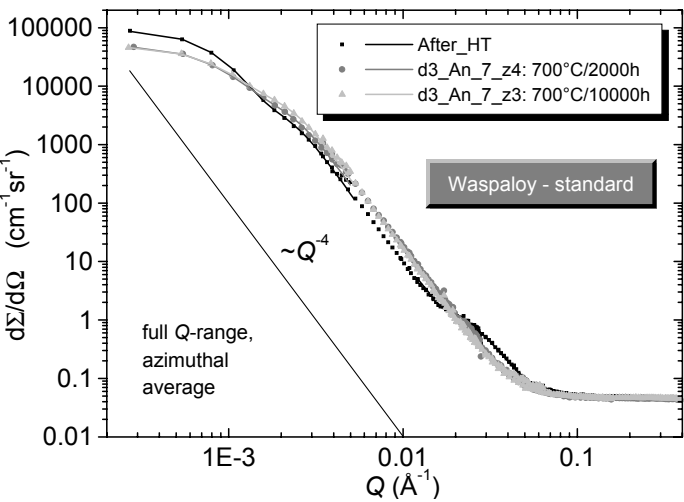

a

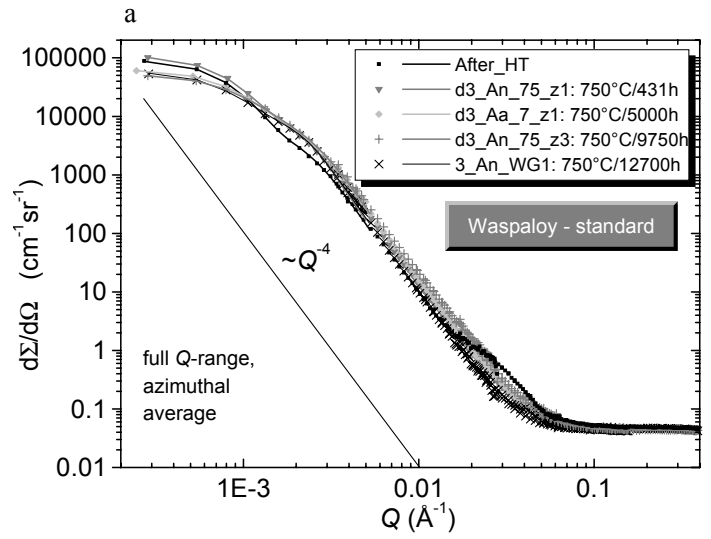

$\mathrm{b}$

Figure 2. Measured and fitted scattering curves of Waspaloy: (a) thermally exposed at $700^{\circ} \mathrm{C}$, (b) at $750^{\circ} \mathrm{C}$. through the symbols which represent the measured data.

Figures $2 \mathrm{a}$ and $2 \mathrm{~b}$ show the measured scattering curves for the standard Waspaloy in the full $Q$ range. There is an extra scattering observable in the pattern (above $Q=0.002 \AA^{-1}$ ), which is superimposed on the scattering background originating from largescale inhomogeneities as carbides or nitrides (this scattering background changes with the slope proportional to $Q^{-4}$ at larger $Q$ values). The increased scattered intensity at around $Q=0.03 \AA^{-1}$ indicates secondary precipitation (i.e. relatively small precipitates) in the heat treated alloy without any additional thermal exposure (figure 2a). These secondary precipitates - precipitated most probably on cooling from the hold temperature during the heat treatment - have the mean (volume weighted) size equal to $150 \AA$, the center-to-center distance of $210 \AA$ and their volume fraction is around $15 \%$. The diagrams do not provide an indication of the presence of secondary precipitates in 


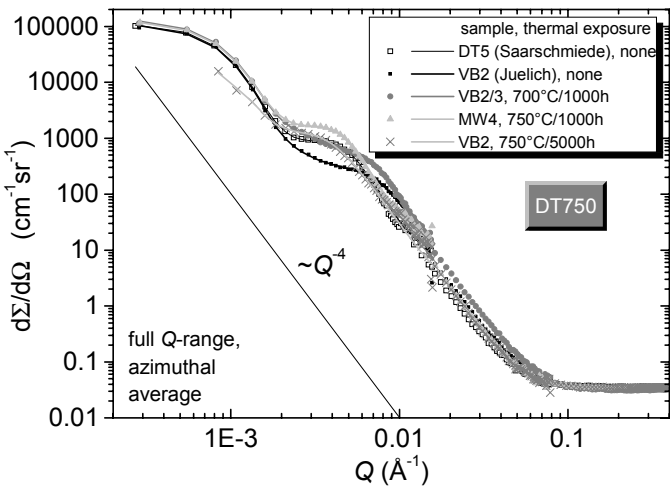

Figure 3. Measured and fitted scattering curves of modified Waspaloy (DT750). the samples exposed both at 700 or $750{ }^{\circ} \mathrm{C}$ in the standard Waspaloy.

Figure 3 displays the detailed measured and evaluated scattering curves for modified (DT750) alloy at low $Q$-values. There is no scattering exceeding the $Q^{-4}$ scattering background as well as constant incoherent background detectable in the modified heat treated alloy (see figure 3 ) at large $Q$-values (i.e. for $Q>0.02 \AA^{-1}$ ). It means that there is no indication of the secondary precipitation for this modified alloy at all.

Increase of the scattering in the low- $Q$ region (i.e. in the range $0.002<\mathrm{Q}<0.01 \AA^{-1}$ ) can be interpreted as an interparticle-interference maximum originating from the relatively dense (20-35\%) population of $\gamma^{\prime}$ precipitates. The microstructural models corresponding to the optimum fits are displayed in figure 4.

\section{Discussion}

The bulk parameters of primary precipitates resulting from the evaluation (mean size, distance and volume fraction of $\gamma^{\prime}$ precipitates) are stated in table 1 . When comparing the standard Waspaloy with its modification DT750, one can recognize much coarser precipitates in standard Waspaloy $(220 \mathrm{~nm})$ than in DT750 (102, respectively $62 \mathrm{~nm})$. The volume fraction of primary precipitates is also larger in DT750 after heat treatment; however, a large part of $\gamma^{\prime}$ volume fraction $(15 \%)$ is occupied by the secondary precipitates (not reported in the table 1) in the standard Waspaloy.

It can be noticed that a large difference exists between the alloys prepared at different places (Saarschmiede, Juelich): the heat treatments are nominally identical but can vary in details (e.g. cooling rates from solution temperature and from the $\gamma^{\prime}$-stabilisation step to RT).

Thermal exposure has then an additional effect on the growth of $\gamma^{\prime}$ precipitates. The evolution of microstructure with thermal exposure is slightly different in both alloys.

\section{Standard WASPALOY}

Even at the shortest thermal exposures, the secondary precipitates disappear on expense of the growth of primary precipitates. The precipitates grow first without significant change of the center-to-center distance (see sample d3_An_7_z4, i.e. $700{ }^{\circ} \mathrm{C} / 2000 \mathrm{~h}$ in table 1 ). Only after this initial period, the distance between the precipitates starts to increase. The volume fraction slightly decreases at the longer exposure times or higher temperature, which could be an indication of dissolution of the smallest precipitates from their size distribution after long-term exposure. 
Table 1. Results of the SANS-data evaluation for all thermal exposures of both superalloys. Volumeweighted values of the mean size are reported.

\begin{tabular}{|c|c|c|c|c|c|c|}
\hline Alloy & Sample name & $\begin{array}{l}\text { heat treat } \\
\text { ment at }\end{array}$ & $\begin{array}{l}\text { thermal } \\
\text { sure }\end{array}$ & $\begin{array}{l}\text { mean } \\
\text { size }(\AA)\end{array}$ & $\begin{array}{l}\text { mean dis- } \\
\operatorname{tance}(\AA)\end{array}$ & $\begin{array}{l}\text { volume } \\
\text { fraction }\end{array}$ \\
\hline Waspaloy & After HT & & none & 2200 & 3180 & 0.10 \\
\hline & d3 An 7 z4 & & $700^{\circ} \mathrm{C} / 2000 \mathrm{~h}$ & 2730 & 3210 & 0.25 \\
\hline & d3 An 7 z3 & & $700^{\circ} \mathrm{C} / 10000 \mathrm{~h}$ & 2870 & 3403 & 0.27 \\
\hline & d3 An 75 z1 & & $750^{\circ} \mathrm{C} / 431 \mathrm{~h}$ & 2820 & 3420 & 0.25 \\
\hline & d3 Aa 7 z1 & & $750^{\circ} \mathrm{C} / 5000 \mathrm{~h}$ & 2950 & 3580 & 0.22 \\
\hline & d3 An 75 z3 & & $750^{\circ} \mathrm{C} / 9750 \mathrm{~h}$ & 2920 & 3830 & 0.20 \\
\hline DT750 & DT5 & Saarschmiede & none & 1020 & 1310 & 0.21 \\
\hline & VB2 & Juelich & none & 620 & 740 & 0.21 \\
\hline & VB2/3 & Juelich & $700^{\circ} \mathrm{C} / 1000 \mathrm{~h}$ & 750 & 800 & 0.35 \\
\hline & MW4 & Juelich & $750^{\circ} \mathrm{C} / 1000 \mathrm{~h}$ & 1190 & 1400 & 0.27 \\
\hline & VB2 & Juelich & $750^{\circ} \mathrm{C} / 5000 \mathrm{~h}$ & 1200 & 1520 & 0.20 \\
\hline
\end{tabular}

\section{DT750}

The sample VB2/3, i.e. the sample with the shortest examined exposure $\left(700{ }^{\circ} \mathrm{C} / 1000 \mathrm{~h}\right)$ exhibits significant increase of the volume fraction of $\gamma^{\prime}$ precipitates with respect to the nonexposed one. This effect occurs without a significant change of the distance of the precipitates. The temperature of exposure $700{ }^{\circ} \mathrm{C}$ is most probably sufficient enough to allow the diffusion of elements and growth of precipitates. On the other side, this temperature is low enough not to cause dissolution of the smaller precipitates in the size distribution. Exposures at higher temperatures $\left(750{ }^{\circ} \mathrm{C} / 1000 \mathrm{~h}\right.$ or $\left.5000 \mathrm{~h}\right)$ results similarly as in the case of standard Waspaloy in coarsening of precipitates and gradual decrease of the volume fraction.

It can be seen that DT750 contains finer primary precipitates also after thermal exposure than Waspaloy (cf. samples d3_Aa_7_z1 and VB2, both exposed at $750{ }^{\circ} \mathrm{C}$ for $5000 \mathrm{~h}$ ).

\section{Conclusions}

The experiment had clearly revealed the secondary precipitation in the standard Waspaloy after the heat treatment. These precipitates, however, are already not present in thermally exposed specimens (at least not with a significant volume fraction). As the secondary precipitation is not observed in DT750 (which was not cooled to room temperature between the
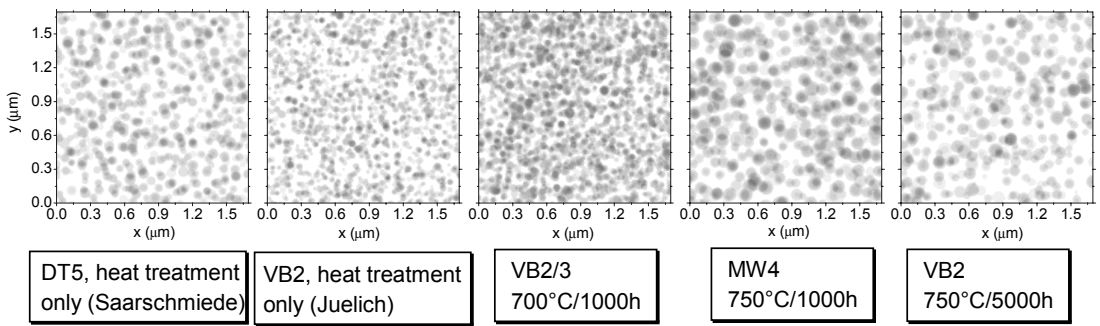

DT5, heat treatment only (Saarschmiede)

VB2, heat treatment only (Juelich)

\section{corresponding to}

$750^{\circ} \mathrm{C} / 5000 \mathrm{~h}$

Figure 4. Sections through the 3D models corresponding to the fitted scattering curves for DT750. 
individual steps of the heat treatment), the creation of the secondary precipitates in the standard Waspaloy occurs most probably on the cooling either from $850{ }^{\circ} \mathrm{C}$ or from $760{ }^{\circ} \mathrm{C}$ to RT during the heat treatment.

The SANS results clearly showed that there are large differences even between samples of the modified superalloy DT750 heat treated at different facilities (Saarschmiede, Juelich). It means that the microstructure of DT750 strongly depends on the details of the heat treatment (e.g. cooling rate).

A strong influence of the thermal exposure on the microstructure of both superalloys was observed which can have an impact on the mechanical properties. When comparing both investigated superalloys, the modified alloy (DT750) exhibits finer dispersion of $\gamma^{\prime}$ precipitates, both after heat treatment and after additional long-term thermal exposure.

\section{References}

1. Durand-Charre, M., 1997, The microstructure of superalloys (Amsterdam, The Netherlands: Gordon and Breach Science Publishers).

2. http://www.specialmetals.com/documents/Waspaloy.pdf

3. Mannan, S., Patel, S. \& deBarbadillo, J., at http://www.specialmetals.com/documents/Long\%20Term\%20Thermal\%20Stability \%20of\%20INCONEL\%20Alloys\%20718,\%20706,\%20725,\%20783,\%20909\%20a nd\%20Waspaloy\%20at\%20593C\%20and\%20704C.pdf

4. Kostorz, G., 1979, in Neutron Scattering (Treatise on materials science and technology), edited by G. Kostorz (NY: Academic Press), 227-289.

5. Zrník, J., Strunz, P., Horňák, P., Vrchovinský, V. \& Wiedenmann, A., 2002, Applied Physics A, 74, 1155-1157.

6. Strunz, P., Mukherji, D., Gilles, R., Rösler, J. \& Wiedenmann, A., 2003, Materials Science Forum, 426-432, 821-826.

7. Strunz P., Gilles R., Mukherji D. \& Wiedenmann A., 2003, J.Appl.Cryst., 36, 854859.

8. Mukherji, D., Strunz, P., Del Genovese, D., Gilles, R., Rösler, J. \& Wiedenmann, A., 2003, Metall. Trans. A, 34, 2781-2792.

9. Strunz, P., Mortensen, K. \& Janssen, S., 2004, Physica B, 350, e783-e785.

Acknowledgements. The support from SINQ (PSI Villigen, CH) enabling to carry out the SANS experiment is gratefully acknowledged. P. Strunz acknowledges the support through the projects GA-CR 202/03/0891, MSM 2672244501 and IRP AV0Z10480505. 